\title{
Investigating the Causes of Students' Less Academic Performance in Engineering College of Debre Berhan University
}

\author{
Hiluf Reda ${ }^{1, ~ *}$, Getahun Mulugeta ${ }^{2}$ \\ ${ }^{1}$ Department of Mechanical Engineering, Debre Berhan University, Debre Berhan, Ethiopia \\ ${ }^{2}$ Department of Statistics, Debre Berhan University, Debre Berhan, Ethiopia \\ Email address: \\ gech.marr@gmail.com(G. Mulugeta),hilufr@gmail.com(H. Reda) \\ ${ }^{*}$ Corresponding author
}

\section{To cite this article:}

Hiluf Reda, Getahun Mulugeta. Investigating the Causes of Students' Less Academic Performance in Engineering College of Debre Berhan University. American Journal of Theoretical and Applied Statistics. Vol. 7, No. 3, 2018, pp. 126-131. doi: 10.11648/j.ajtas.20180703.15

Received: March 22, 2018; Accepted: April 8, 2018; Published: April 28, 2018

\begin{abstract}
Student success is a critical issue facing higher education today. Schools, colleges and universities have no worth without students. Students are most essential asset for any educational institute. Less academic performance of students in universities especially in engineering colleges and its ripple effects are looming dangers for Ethiopia. The main purpose of this research is to identify and examine factors that affect students' academic performance at DBU College of engineering. To achieve this objective a sample of 263 students have taken and self-administered questionnaires were distributed through the selected respondents. Both descriptive and inferential statistics were employed. From the descriptive result of the study it has shown that the average CGPA of engineering student is 2.93 with minimum of 2.00 and maximum of 3.96 . From multiple linear regression result it is evident that student interest, study habit and previous background factors have a significant effect on the academic performance of students. From the result of the study it is concluded that assigning departments based on the interest of students, effective study habit and good previous background enhances the performance of engineering students. And it is recommended that Orientation and special training should be given for fresh students about effective study habit at the very beginning of the academic year, a continuous and strategic work should be done on students at the lower grades in line with engineering departments in the university, assigning of departments should be conducted based on the interest of students and finally this research should be implemented as project work to enhance the performance of engineering students.
\end{abstract}

Keywords: Engineering Students, Academic Performance, Multiple Linear Regression, Debre Berhan University

\section{Introduction}

\subsection{Background of the Study}

Education is vital in producing human resource for the economic development of a country. Education, in a broad sense, is any act or experience that has a formative effect on mind, character or physical ability of an individual [3]. The role of education plays and contributes to intellectual growth and development of society which becomes the common concern in both developed and developing countries [6]. The quality of educational system of any country may reflect the development attempts to be made in social, economic and political aspects. Furthermore, in this era of globalization and technological revolution, education is considered as a first step for every human activity. It plays a vital role in the development of human capital and is linked with an individual's well-being and opportunities for better living [4]. It ensures the acquisition of knowledge and skills that enable individuals to increase their productivity and improve their quality of life. This increase in productivity also leads towards new sources of earning which enhances the economic growth of a country [2]. The quality of students' performance remains at top priority for educators. It is meant for making a difference locally, regionally, nationally and globally. Educators, trainers, and researchers have long been interested in exploring variables contributing effectively for quality of performance of learners. 
Schools, colleges and universities have no worth without students. Students are most essential asset for any educational institute [7]. The social and economic development of a country is directly linked with student academic performance. The students' performance (academic achievement) plays an important role in producing the best quality graduates who will become great leader and manpower for the country thus responsible for the country's economic and social development [1]. Student academic performance measurement has received considerable attention in previous research, it is challenging aspects of academic literature, and science student performance are affected due to social, psychological, economic, environmental and personal factors [9]. These factors strongly influence on the student performance, but these factors vary from person to person and country to country. Indeed, academic performance can be influenced by some many factors these variables are inside and outside school that affect students' quality of academic achievement. These factors may be termed as student factors, family factors, school factors and peer factors [5]. Consequently, Student academic performance measurement has received considerable attention in previous research, it is challenging aspects of academic literature, and science student performance are affected due to social, psychological, economic, environmental and personal factors. These factors strongly influence on the student performance, but these factors vary from person to person and country to country [13].

Since the introduction of modern education in Ethiopia, Ethiopians have recognized the need to improve the quality of education and increase students' academic performance. Ethiopians have never been, however, as concerned about the students' academic performance in Ethiopia as today. Less academic performance of students in universities especially in engineering colleges and its ripple effects are looming dangers for Ethiopia [8]. The problem is systemic and mainly intentionally induced. Debre Berhan University (DBU) is one of the Ethiopia higher educations. And Institution of technology and college of engineering is one of the institution and College of DBU. Hence addressing this issue should be one of the top priorities for DBU College of Engineering. The core idea of this research is to identify the root causes of students less academic performance in DBU college of Engineering and implementing the solutions as a project work.

\subsection{Statements of the Problem}

In Ethiopia the academic performance of students and quality of education are decreasing from time to time especially in Universities, engineering colleges [14]. Complain about the students' academic performance from external customers, higher officials, industries, governmental and non-governmental offices is increasing from year to year. This can be an indicator that our customers are not satisfied about the academic performance of our graduated students. Hence it needs a solution [12].

Ethiopian Ministry of education is also giving its witness that most of the university graduates have less performance in doing what their profession is demanding. They are graduated almost only in paper; which means they don't have enough knowledge and skills about their profession [11].

In addition to this; the failure rate of student in engineering college is much greater than that of other colleges in DBU.

Generally students' academic performance in engineering college is decreasing from time to time. On the other hand this college has so many engineers in which they are expected to solve any problems as engineers. Now a day's cheating is also becoming as a fashion instead of reading different reference books and literatures and getting good performance of his/her own self.

Hence graduating unqualified, not well skilled and incapable citizen is a waste for the country and for DBU College of engineering. Because Ethiopia is a developing country it should use the limited available resources effectively and efficiently. In addition to this less academic performance graduates will not be competitive in this competitive world and will not contribute for the development of the country as intended; instead they will be setback for the development of the country. This is the critical issue for DBU College of Engineering as well as for Ethiopia as a developing country.

The main objective of this research is to analyze the root causes of students' low academic performance in engineering college.

Specifically the paper aimed to:

To examine the existing students' academic performance.

To analyze the factors that affect students' academic performance.

To identify the root causes of students' low academic performance.

\section{Method}

\subsection{Data Source}

The type of data that was employed under this study is primary data from sampled respondents in the college of engineering. The data was collected by trained data collectors using a standard, structured and pre-tested questionnaire. In order to minimize the errors in data collection that may be introduced by the enumerator, training was provided for four days.

\subsection{Sampling Design}

The target population for this study was all college of engineering students except first year students. Before the actual data collection, emphasis was done on the determination of sample size depending on the purpose of the study, available resource and precision required.

In this study, a probabilistic sampling (stratified random sampling) technique was adopted as an appropriate sampling method for selecting a representative sample of the engineering students. The stratification in this study was based on the batch of students. Four batches (strata) were considered. Batch two represents stratum one and up to batch five represents stratum four. 


\subsection{Sample Size Determination}

Determining the sample size for a study is a crucial component of study design. The goal is to include sufficient numbers of subjects so that statistically significant results can be detected. In order to have an optimum sample size, there are a number of issues/points one has to take into account. Some of the issues are: objective of the research, design of the research, cost constraint, plan for statistical analysis, degree of precision required for generalization, degree of confidence with which to conclude etc. As mentioned in sampling design, sample size determination technique used in this study was stratified random sampling techniques. Accordingly, the sample size determination formula adopted for this study was

$$
\mathrm{n}_{\mathrm{o}}=\frac{(\mathrm{Z} \alpha / 2)^{2} * \delta^{2}}{d^{2}}
$$

Where $\mathrm{d}$ is acceptable margin of error $=5 \%, \mathrm{Z}$ is the critical values of standard normal cumulative distribution that corresponds $\alpha / 2, \alpha$ - level of significance $\left.{ }^{(\mathrm{Z}}{ }_{0} .25=1.96\right)$

Since $\delta^{2}$ is not known so it is estimated by $\mathrm{S}^{2}$ in order to estimate $S^{2}$ it is a must to conduct pilot survey

What is your CGPA----------? By asking 30 students from different batch:

$$
\mathrm{s}^{2}=\sum=\frac{(x i-\bar{x}) 2}{n p-1}=0.155
$$

Where $\mathrm{x}_{\mathrm{i}}=$ observation (CGPA for each student)

$\bar{X}=$ mean of observation (average CGPA)

$\mathrm{n}_{\mathrm{p}}=$ number of students we asked

Then $\mathrm{n}_{\mathrm{o}}=\frac{(\mathrm{Z} \alpha / 2)^{2} * \mathrm{~s}^{2}}{d^{2}}=\frac{(3.84)(0.155)}{0.0025}=238$

Note if $\frac{n o}{N}>5 \%=0.072>5 \%, \mathrm{n}_{\mathrm{o}}$ is adjusted by $\mathrm{n}=\frac{n o}{1+\frac{n o}{N}}$

Since $\frac{n o}{N}=\frac{238}{3321}=0.072>5 \% \mathrm{n}=\frac{n o}{1+\frac{n o}{N}}=\frac{238}{1+0.072}=222$.

The final sample size with $5 \%$ non-response rate becomes:

$$
\mathrm{n}+5 \% \mathrm{n}=222+11=233
$$

Therefore the final sample size for this study is 233 .

Once the sample size has been determined, it was proportionally allocated for each batch as follow

$$
\begin{gathered}
\mathrm{n}_{\mathrm{h}}=\frac{N h}{N} * \mathrm{n} \mathrm{h}=1,2,3,4 \\
\mathrm{n}_{1}=\frac{748}{3321}(233)=52\left(2^{\text {nd }} \text { year }\right) \\
\mathrm{n}_{2}=\frac{748}{3321}(233)=52\left(3^{\text {rd }} \text { year }\right) \\
\mathrm{n}_{3}=\frac{713}{3321}(233)=51\left(4^{\text {th }} \text { year }\right) \\
\mathrm{n}_{4}=\frac{1112}{3321}(233)=78\left(5^{\text {th }} \text { year }\right)
\end{gathered}
$$

\subsection{Variables Considered in the Study}

\subsubsection{Dependent Variables}

The response variable of the study is performance of students. It can be measured by cumulative grade point average (CGPA). So CGPA was considered as the dependent variable, which is continues variable, can be analyzed through regression analysis.

\subsubsection{Independent Variables}

The independent variables assuming to influence performance of students are:-

Student's interest .

Student's habit.

Previous background.

Instructors related factors.

Organizational related factors.

\subsection{Method of Analysis}

Statistical tools that have applied under this study were regression analysis and simple descriptive measures like; mean, standard deviation, frequency distribution and different graphs and diagrams.

\subsubsection{Multiple Linear Regressions}

Multiple linear regressions explain the relationship between two or more independent variables and a response variable by fitting linear equation.

The general formula for multiple linear regression model of p-explanatory variables is defined to be:

$$
\mathrm{Yi}=\beta_{0}+\beta_{1} \mathrm{X}_{1}+\beta_{2} \mathrm{X}_{2}+\beta_{3} \mathrm{X}_{3}+\ldots \ldots \ldots \ldots+\beta_{\mathrm{p}} \mathrm{X}_{\mathrm{P}}+\mu_{\mathrm{i}}
$$

Where, $\mathrm{Yi}$ is dependent variable (academic performance)

$\mathrm{X}^{\prime} \mathrm{s}$ are independent variables.

$\beta_{0}$ is constant parameter.

$\beta$ 's are coefficient parameters.

$\mu \mathrm{i}$ is residual due to measurement error.

Assumptions of multiple linear regressions.

1. $\operatorname{Var}\left(\mu_{\mathrm{i}}\right)=\delta^{2}$, the error term should have constant variance (homoscedasticity).

2. The error term is independently and identically distributed random variable having normal distributed with mean 0 and variance $\delta 2$ i.e it distribute $\mathrm{N}\left(0, \delta^{2}\right)$.

3. X's -are independent (no Multicolinearity) each other.

4. Explanatory variables and error term are uncorrelated.

5. There is no autocorrelation between error terms.

Estimation of Model Parameters.

The most popular method of estimating the multiple linear regression parameters $(\beta)$ is least square method. Least squares method is a method that obtains an estimate of $\beta$ which minimizes the sum of square deviation of the observed values of the dependent variable $(\mathrm{Y})$ from its function $\mathrm{E}(\mathrm{Y})=$ $\mathrm{X} \beta$.

Hypothesis testing.

i. Test of overall model parameter.

Step 1: The overall goodness of the model (the model is not significant) vs $\mathrm{H} 1$ : at least one different from zero (the model is significant.

Step 2: Specify $\alpha$ level of significant.

Step3: Test statistics.

$\mathrm{f}_{\mathrm{cal}}=\mathrm{MSR} / \mathrm{MSE}$, where $\mathrm{MSR}=$ the regression mean square 
with p-1 degree of freedom, MSE=mean square of error with $n-p$ degree of freedom.

Step 4: Decision: If $\mathrm{f}_{\text {cal }}>\mathrm{f}_{\text {tab }}$ or $\mathrm{p}$ value $<\alpha$ then Ho will be rejected at a given significance level.

Step 5: give conclusion based on the above decision.

ii. Test of individual parameter.

Step 1: Ho: $\beta i=0$ vs. H1: $i \neq 0 . i=1,2,3 \ldots \ldots . . p$

Or Ho: the variable has no significant effect on the response variable $\mathrm{H} 1$ : the variable has a significant effect on the response variable.

Step 2: Specify $\alpha$ level of significant.

Step3: Test statistics For Small sample $(\mathrm{n}<30), \mathrm{t}_{\text {call }}=$ $\beta / \operatorname{se}(\beta)$.

Step 4: Decision $t_{c a l}>t_{\text {tab }}{ }^{n-p}$ or $p$ value $<\alpha$, then reject Ho at a given significant level $(\alpha)$.

Step 5: give conclusion based on the above decision.

\section{Result and Discussion}

The main objective of the study is identifying factors affecting student's academic performance of engineering students in Debre Berhan University. Both descriptive and inferential statistical analyses were employed. SPSS v.20 was used for analysis purpose. Descriptive statistics has used to assess the existing situation of academic performance of engineering students, whereas inferential statistics has used to investigate the relationship between academic performance and the set of predictor variables.

\subsection{Descriptive Result}

Descriptive result of the study shows that the average CGPA of engineering students is 2.93 with maximum of 3.96 and minimum of 2.00 .

\subsection{Inferential Result}

It is advanced portion of statistics which can be generalized and concluded about the population from the sample results. The main problem with any univariate approach is that it ignores the possibility that a collection of variables, each of which is weakly associated with the outcome, can become an important predictor of the outcome when taken together [10]. Hence, multiple linear regression has been used to investigate the relationship of academic performance and the set of predictor variables.

Basically multiple linear regression has three basic output namely; model summary, Anova table and coefficient table.

Adjusted R Square in the model summary table below shows the degree of explanation of the dependent variable by the model. The result reveals that about $60.6 \%$ of the variability in performance of students is explained by the set of predictor variables in the model. Actually the value of adjusted $\mathrm{R}$ square inflated when the number of predictor variables increased in the model. So in this study the model is well explained. The last column, Durbin Watson test shows absence of autocorrelation (additional assumption of MLR, errors must be uncorrelated).
Table 1. Model summary.

\begin{tabular}{lllll}
\hline R & R Square & $\begin{array}{l}\text { Adjusted R } \\
\text { Square }\end{array}$ & $\begin{array}{l}\text { Std. Error of the } \\
\text { Estimate }\end{array}$ & $\begin{array}{l}\text { Durbin- } \\
\text { Watson }\end{array}$ \\
\hline .784 & .614 & .606 & 24.65982 & 1.395 \\
\hline
\end{tabular}

Analysis of variance (F-test) part of regression analysis shows that the overall model is significant or not. Referring the last column of table 4.6 (Sig. $=.000$ ) reveals that the regression model is highly significance to fit the data. And the cumulative effect of the set of predictor variables on the response variable is highly significance, but it doesn't show which predictor variable make the model significance, which can be examined by the coefficient table (t-test) in table 2 below.

Table 2. Anova Table.

\begin{tabular}{llllll}
\hline $\begin{array}{l}\text { Source of } \\
\text { variation }\end{array}$ & $\begin{array}{l}\text { Sum of } \\
\text { Squares }\end{array}$ & df & Mean Square & F & Sig. \\
\hline Regression & 248464.127 & 5 & 49692.825 & & \\
Residual & 156283.386 & 257 & 608.107 & 81.717 & .000 \\
Total & 404747.513 & 262 & & & \\
\hline
\end{tabular}

The coefficient table or t-test of regression analysis shows the effect of each predictor variable on the response variable. Refereeing significance level of each predictor variables shows that from nominated 5 independent variables 3 of them have highly significant effect on student's academic performance of. From the table it has shown that; student interest, study habit and previous background have a significance effect on performance of students at $5 \%$ level of significance. The fitted multiple linear regression equation is given by:

$$
\mathrm{Yi}=3.178+.330 \mathrm{X}_{1}+.367 \mathrm{X}_{2}+.063 \mathrm{X}_{3}+.072 \mathrm{X}_{4}+.179 \mathrm{X}_{5}
$$

Where $\mathrm{Yi}$ is the CGPA (academic performance) and $\mathrm{X} 1$ is student interest factors, $\mathrm{X} 2$ is Student study habit factors, $\mathrm{X} 3$ is instructor related factors, $\mathrm{X} 4$ is organizational factors and $\mathrm{X} 5$ is previous background factors. The set of predictor variables listed in the coefficient table, and the regression coefficients $\beta \mathrm{i}$ for each predictor variable also given in the above table. From the table above it has shown that student interest is highly significant with $\mathrm{B}=0.330$ and $\mathrm{p}=0.00$. This indicates that when the student interest factors like; preparation of students for engineering courses, listing and participating in the class, conducting individual assignments by themselves, ambition of scoring good grade, never missing any class, participating on group assignments, being active to get information and studying engineering courses interestingly enhance student's academic performance.

The coefficient table above has shown that student study habit is highly significant with $B=0.367$ and $p=0.00$. This indicates that when the student study habit factors like; studying all the courses based on studying program, exerting more effort when difficult assignments occurs, spending vacant time in studying the lessons, study the lesson missed in case of absent from class, prepared for quizzes and tests ahead, usually studying harder to improve students' performance, non-use stimulants like chat, alcohol...etc for 
study purpose, often doing assignments on time, extracurricular activities hinder studies, usually studying the books available in the library in addition to the notes given by the instructor and having a habit of asking classmate as well as teacher when there is unclarity increases students' academic performance.

It has also shown that students previous background factors is highly significant with $\mathrm{B}=0.179$ and $\mathrm{p}=0.000$. This indicates that when the previous background related factors like; being among the top students in secondary education, have basic knowledge of mathematics and science subjects in the lower grades, have no problem in reading and understanding most of the problems/exercises, didn't get frustrated when instructor enters in to the class and good university entrance result or grade 12 result enhance the performance of students. Hence is necessary to work in the lower grades to improve students' academic performance especially in English, Mathematics and science courses.
But as it has shown above instructor related and organizational factors have no such expected significant influence on the academic performance of engineering students at 5\% level of significance. So, special attention should be given for student related factors like student interest, study habit and previous background. From the result of analysis it is evident that assigning departments based on the interest of students plays a vital role for the successful accomplishment of students. Study habit also has its own undue influence on student academic achievement so a special orientation and training should be given for fresh students about effective study habit of university students. As it has shown from the result previous background of students has very important role on the performance of students in the university. In order to promote the performance of students in the university a continuous and strategic work should be done on the students at the lower grade before coming to the university.

Table 3. Coefficient table.

\begin{tabular}{lllll}
\hline \multirow{2}{*}{ Variables } & \multicolumn{2}{l}{ Unstandardized Coefficients } & \multicolumn{2}{l}{ Standardized Coefficients } \\
\cline { 2 - 3 } & B & Std. Error & Beta & \\
\hline (Constant) & 3.178 & 4.554 & & .341 \\
student interest factors & .241 & .037 & .330 & 6.504 \\
Student study habit factors & .273 & .044 & .367 & .000 \\
instructor related factors & .048 & .036 & .063 & .191 \\
organizational factors & .062 & .034 & .072 & .323 \\
previous background factors & .126 & .032 & .179 & .015 \\
\hline
\end{tabular}

\section{Conclusions}

From the literature review, different scholars give the definition of quality and quality of education. And most of the literatures list different factors that affect students' academic performance.

The descriptive result of the study shows that the average CGPA of engineering students is 2.93 with maximum of 3.96 and minimum of 2.00 . From the inferential analysis of the study it is evident that student interest, study habit and Previous back ground factors have highly significant effect on the students' academic performance. That is assigning departments based on the interest of students, effective study habit and previous academic background promote the academic achievement of students in the university.

Even if instructor related and organizational factor have no such expected undue influence on the academic performance of students, it has moderate influence on the academic achievement of students on the result of the study. From the result it is evident that interesting lecturing methods like student centered, well preparation of instructors and good experience of teachers have enhance the academic achievement of students. On the other hand organizational factors like, access of reading materials in the library, suitability of class rooms and dormitory and accessibility and well equipment of workshop and laboratory enhance the achievement of engineering students in the university.

Generally from the result of this study it can be concluded that student related factors are the most dominant predictors that have undue influence on the academic performance of students. So, special attention should be given for students' interest, study habit and previous background to enhance the academic achievement of engineering students.

\section{Recommendations}

From the result of the study the following recommendations were forwarded:

Entrance exam should be given so that it will help to identify the status of the students' academic performance.

Assigning of departments should be conducted based on the interest of students.

Orientation and special training should be given for fresh students about effective study habit at the very beginning of the academic year.

A continuous and strategic work should be done on students at the lower grades in line with engineering departments in the university.

Students should practice by themselves in the laboratories and workshops after the demonstration given by the instructors.

Most of the students didn't know that their workshops and laboratories are well equipped; department heads should show their workshops and laboratories

The university should fulfill and make suitable the facility of teaching and learning process, like class room, library, dormitory and cafeteria.

It is highly recommended to give communication skill 
training to the instructors.

This research should be implemented as a project work.

\section{References}

[1] Victor Mlambo "An analysis of some factors affecting student academic performance in an introductory biochemistry course at the University of the West Indies", Caribbean Teaching Scholar, Vol. 1, No. 2, November 2011, 79-92.

[2] Syed Tahir Hijazil and S. M. M. Raza Naqvi2, "Factors affecting students' performance" Bangladesh e-Journal of Sociology. Volume 3. Number 1. January 2006.

[3] Norhidayah Ali1, et al. "The Factors Influencing Students' Performance at University Technology MARA Kedah, Malaysia”, Management Science and Engineering Vol. 3 No. 4 2009.

[4] Barbra Mapuranga, et al., "Students Perceptions on Factors that affect their Academic Performance: The Case of Great Zimbabwe University (GZU)", Journal of Education and Practice, Vol. 6, No. 18, 2015.

[5] Irfan Mushtaq \& Shabana Nawaz Khan, "Factors Affecting Students' Academic Performance", Global Journal of Management and Business Research, Volume 12 Issue 9 Version 1.0 June 2012.

[6] Elisa Rose Birch and Paul W. Miller, "The Determinants of Students' Tertiary Academic Success", University of Western Australia, June 2005.

[7] Llie G. and. Ciocoiu C. N., "Application of fishbone diagram to determine the risk of an event with multiple causes", MANAGEMENT RESEARCH AND PRACTICE Vol. 2 Issue 1,2010

[8] DHS (2005) Demographic and Health Survey. Central Statistical Authority, Addis Ababa, Ethiopia.

[9] Hans F. M. Crombag, "On defining quality of education", Educational Research Center, University of Leyden, The Netherlands, Higher Education, Vol. 7, No. 4 (Nov., 1978)

[10] Hosmer, D. W and Lemeshow, S., 1989. Applied logistic regression. 2nd Edition John Wiley and Sons, Inc; New York.

[11] Emmanuel Adjei Frimpong, et al., "Institutional Factors Affecting the Academic Performance of Polytechnic Students in Ghana" International Journal of Humanities \& Social Science Studies (IJHSSS), Volume-II, Issue-V, March 2016.

[12] Agharuwhe A. Akiri, "Effects of Teachers' Effectiveness on Students' Academic Performance in Public Secondary Schools; Delta State - Nigeria", Journal of Educational and Social Research, MCSER Publishing, Rome-Italy, Vol. 3 No. 3 September 2013.

[13] Dhani. Shanker Chaubey, et al., "Analysis of the Factors Influencing Academic Performance of Student Using Discriminant Function", International Journal of Engineering and Management ResearchVolume-6, Issue-3, May-June 2016.

[14] Geremew Muleta et al., "Factors that Influences Students Academic Performance: A Case of Rift Valley University, Jimma, Ethiopia", Journal of Education and Practice, Vol. 6, No. 22, 2015. 